\title{
Be (and have) good neighbours! Factors of vulnerability in the case of multiple hazards
}

\author{
Francesco Pagliacci*,1, Margherita Russo ${ }^{2}$ \\ Dipartimento di Economia Marco Biagi, and CAPP (Centro Analisi Politiche Pubbliche), Università degli Studi di Modena e Reggio Emilia, Viale Berengario 51, 41121 \\ Modena, Italy
}

\section{A R T I C L E I N F O}

\section{Keywords:}

Social and material vulnerability indicators

Multi-hazard

Disaster Risk Reduction

Neighbouring effect

\section{JEL codes:}

Q54

R11

R58

\begin{abstract}
A B S T R A C T
For any given territory, disaster risk is a function of hazard, exposure and vulnerability. The conceptual frameworks for these dimensions are largely debated in the scientific studies, focusing on spatial and temporal references and on system perspective of risk assessment. Despite broad in their scope, the analytical frameworks proposed to analyse policy programmes to reduce risk generally miss that risk indicators should be grounded on geographical and spatial features of the neighbouring territories and not only on communities' behaviour, and their resilience, as the paradigmatic solution in front of system events in areas prone to natural multi-hazard. The definition of "community" and of "neighbourhood" that are relevant for risk assessment cannot be simply defined in terms of absolute size of population or economic activity of individual local units under analysis or of the formal aggregation provided by jurisdictional agreements on specific functions. The paper presents an empirical analysis on spatially-lagged data in Italy, which was massively hit by adverse natural events in the last decade. It suggests to focus on social and material vulnerability, by using the comprehensive indicator at municipality level elaborated by the Italian Institute of Statistics. At the municipality-level, the analysis shows a positive correlation between multi-hazards, on the one hand, and spatially-lagged exposure and vulnerability, on the other. Thus, conditions in neighbouring municipalities would matter in prioritizing policy interventions aiming at mitigating hazard impacts, reducing vulnerability and enhancing communities' resilience. The definition of significant neighbouring spaces opens to a conceptualization of vulnerability grounded on a relational perspective in the creation of collective goods. This could enhance more effective Disaster Risk Reduction programmes.
\end{abstract}

\section{Introduction}

In the last decade, Italy experienced a series of major natural disasters $^{3}$ that have produced severe socioeconomic damages. Recovery plans have only started in some areas and the national debate on the need for prevention interventions fluctuates in the ups and downs of the emergency. In science policy, it is well recognized that major events become the leverage for major policy changes (Clarke and Chenoweth, 2006; Bowman and Parsons, 2009): this was the case of the terroristic attack of September 11, 2001 in the United States (Clarke and Chenoweth, 2006) and the reaction of the major 2016 earthquake in Central Italy (Pagliacci et al., 2017), where the need to overcome unpreparedness appeared to be particularly urgent. With regard to Italy, in 2016, all the political parties in the Parliament approved a national plan for action, addressing the need for interventions to have safer buildings and physical infrastructures ("Casa Italia" Plan, see Pagliacci et al., 2017).

Three years after its approval, no systematic policy intervention has been implemented and only some pilots have been undertaken (under the "Casa Italia" Plan), although such interventions would be of utmost importance in Italy, the European country with the highest probability of disasters and related economic losses (Beck et al., 2012; Frigerio and De Amicis, 2016; Valensise et al., 2017; Marin et al., 2019). After the urgency of providing an answer to the emergency situation, the

\footnotetext{
* Corresponding author.

E-mail addresses: francesco.pagliacci@unimore.it (F. Pagliacci), margherita.russo@unimore.it (M. Russo).

${ }^{1}$ ORCID: 0000-0002-3667-7115.

${ }^{2}$ ORCID: 0000-0002-7277-1002.

${ }^{3}$ Earthquakes occurred in L'Aquila (2009), Emilia-Romagna (2012) and Centre Italy (2016). There have been many severe floods, such as the ones in Vicenza and

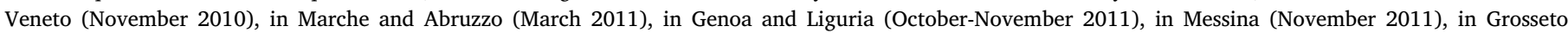

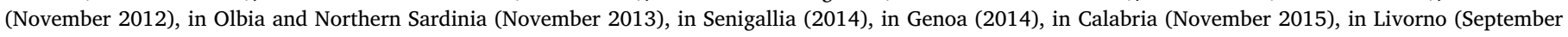
2017), in Sicily near Palermo (November 2018).
} 
complex and long-term process of prevention is hampered not so much by the lack of funds as by the difficulty of taking a political decision to start actions in some specific places and directions. Given that vulnerability and natural hazard are ubiquitous, when one moves from national plan to local actions, multi-level governance coordination is advocated as a critical issue, together with the need for appropriate competences, adequate funds and policy commitment, but - on the top of those critical dimensions - the local dimension of interventions is crucial in making actions effective. Relying on the resilience of local communities and interventions of local governments is generally stressed as a major leverage for risk reduction, also in the Sendai Framework (UNISDR, 2015). Moving from the ecological notion (Martin and Sunley, 2015), adaptive resilience becomes the paradigmatic solution for bouncing forward (and not only bouncing back) community conditions. However, it is not clear to which extent and in what conditions communities' resilience can be enhanced.

In analysing the strategies enacted by local municipalities hit in Italy by a major earthquake occurring in Emilia in 2012, Bertolini et al. (2016) observed different strategic behaviour and performance of local municipalities that were involved in formal aggregations, grounded on jurisdictional agreements on specific functions (e.g., social or educational services, transport infrastructure or health services). Some small municipalities that, before the earthquake, had already practiced cooperation with neighbouring cities were experiencing a greater resilience in front of natural hazards, while in other cases the mere existence of a formal aggregation of municipalities was not robust enough to support communities' resilience. ${ }^{4}$ Analogous to such results are the findings of the research conducted by Bowman and Parsons (2009) on small cities in five counties in the US. They suggest that local government that have established performance regimes are more effective in tackling the complex management of extreme events ${ }^{5}$.

Moving from empirical case studies to the definition of the analytical framework to be adopted for policy interventions, the definition of significant neighbouring spaces opens to a conceptualization of vulnerability grounded on a relational perspective, thus orienting Disaster Risk Reduction programmes towards the public and private interventions that would be more effective in enhancing communities' resilience by supporting local performance regimes. In such framework, an array of analyses of specific dimensions of natural hazards and vulnerabilities has been proposed, with increasing attention devoted to the role of resilient communities as a leverage for policy programmes aiming at mitigating the impact of multi-hazard areas. Although broad in their scope, the analytical frameworks supporting policy programmes generally miss that risk indicators should be grounded on geographical and spatial features of the neighbouring territories and not only on individual communities' behaviour, as if it were the paradigmatic solution of system events in areas prone to multi-hazard. The definitions of "community" and of "neighbourhood" that are relevant for such risk assessment should be made operational. Broadly speaking, community is associated to the population living in a given administrative unit (see, for example, Cutter et al., 2008; 2014). Neighbourhood cannot be simply defined in terms of absolute size of population or economic activity of individual local units under analysis (e.g. the municipalities) or in terms of the formal aggregation provided by jurisdictional agreements on specific functions (for example with regard to social or educational services, transport infrastructure or health services). In

\footnotetext{
${ }^{4}$ In the context of that empirical analysis, resilience referred to the implementation of short-term solutions, supporting the recovering of services or providing temporary housing for population and venues for economic activities (Pagliacci and Russo, 2019b).

${ }^{5}$ The notion of "local performance regimes" was first elaborated by Clarke and Chenoweth (2006). Their contribution was inspired by the seminal work of Clarence Stone in 1989, but they significantly changed the perspective on relevant actors and the conditions of the effectiveness of their interactions over time.
}

order to address this issue at the country level, it would be necessary to rely on an indicator of community resilience at municipality level, in the relational context, defined also in a spatial perspective. Alternatively, the paper investigates to which extent interdependences of multi-hazard, exposure and vulnerability of neighbouring municipalities matter. The paper presents an empirical analysis on spatiallagged data focusing on social and material vulnerability, by using the comprehensive indicator at municipality level elaborated by the Italian Institute of Statistics (ISTAT) ${ }^{6}$.

Grounded on the results by Pagliacci and Russo (2019a), who return an empirical analysis at municipality level of the territorial distribution of multi-hazards, exposure and vulnerability in Italy $^{7}$, this paper considers the additional role played by neighbouring territories, in terms of their exposure and socio-material vulnerability. Elaborating on this analytical framework is important in all countries, where mitigating the potential impact of multi-hazard calls for huge investments and longterm planning, covering the whole country. This situation demands data, analytical tools and indicators, for prioritizing investments. To do this, the analysis is carried out on municipality-level data, by referring to Exploratory Spatial Data Analysis (ESDA). The paper has a strong policy focus and the methodology aims to be of use for any DRR measure that could largely benefit from a spatially-tailored approach, and specifically for Italian decision makers who can implement it immediately.

The argument presented in the paper is structured as follows. The second section briefly refers to the debate on risk and vulnerability, in order to outline the perspective adopted in the paper. The third section describes the case study (Italy and its long history of disasters), explaining why it is important to assess the role of neighbouring areas when considering adverse natural events. The fourth section describes data and methods for tackling this issue and returns the key elements of the implementation of ESDA on this topic. The fifth section returns the main results, and the sixth section discusses them under the light of the territorial imbalances in the country, also providing some policy implications. The seventh section concludes the work, pointing out future research strands.

\section{Term of reference on vulnerability and risks, and place-based interventions}

According to the Disaster Risk Reduction (DRR) framework, while the "forces of nature" play a key role in a disaster (Costanza and Farley, 2007, p. 249), this is also the outcome of human (and economic) decisions (UNISDR, 2015). Thus, since the 1990s, the socio-economic discourse on disasters has focused on the statistical tools and indicators to assess risks (Cutter et al., 2003; Cardona, 2005; Frigerio and De Amicis, 2016, Birkmann, 2007; Bollin and Hidajat, 2006; Schumacher and Strobl, 2011). These contributions rely on a common economic principle, according to which disaster risk is the compound function of natural hazard (namely, a threat of an adverse natural event that might

\footnotetext{
${ }^{6}$ Although specifically applied to Italy, the paper focuses on a critical issue in the current debate on Disaster Risk Reduction and on development policies, whose importance goes beyond its country relevance, in particular in the European Union where interrelations among territories is component of designing macroregional policies (implemented in the programming periods 2007-2013 and 2014-2020). In those policies, socio-economic synergies and complementarities in the neighbouring space are the leverage for designing the development path of the macroregion. Most of the issues debated in those policies are at the core of the local performance regimes that should support local prevention plans of Disaster Risk Reduction: in which way a shared vision can be created, which inter-governmental co-ordination could support the initiatives, which are the public and private stakeholders that must be mobilized, what incentives can orient private and public behaviours.

${ }^{7}$ Data can be freely accessed online, at http://hdl.handle.net/11380/ 1184020
} 
have a negative effect on humans and assets), exposure (which includes all the elements at risk, e.g. people and their material and immaterial economic assets), and vulnerability (i.e., all those physical, social, economic and environmental factors that may increase the susceptibility of individuals, communities, assets or systems to the impacts of hazards) (Wisner et al., 2004; UNDRR, 2004; UNISDR, 2015; Frigerio and De Amicis, 2016).

In order to assess and compare risk across different communities (or areas), empirical strategies have adopted mathematical formulations (Dao and Peduzzi, 2003; Peduzzi et al., 2009; Cardona et al., 2012; UNDRO, 1980), with risk being expressed as a function of hazard, exposure, and vulnerability. While hard sciences have provided indicators on the different types of hazard, socioeconomic statistics has returned figures of exposure. Conversely, the concept of vulnerability itself remains largely debated, with definitions that differ across and within disciplines. In defining a conceptual framework of vulnerability in the context of climate change, Füssel (2007) suggests to consider six dimensions: system (such as human-environment, population group, economic sector); temporal reference (current vs. future vs. dynamic); scale (internal vs. external vs. cross scale); knowledge domain (socioeconomic vs. biophysical vs. integrated); attribute of concern (such as the human lives and health, cultural identity of a community, the biodiversity); hazard (discrete vs. continuous). It is clear that vulnerability not only refers to a physical and material fragility (as it was considered in the 1970s and the 1980s) (Birkmann, 2007), but it also encompasses social dimensions.

The mathematical formulation of risk appears ineffective because of the general lack of data at the appropriate time-space granularity, the specific meanings to be assigned to the operators combining the determinants of risk, and because risk assessment should encompass direct and indirect effects in the set of calculations ${ }^{8}$. Moreover, since generally neither natural hazards nor exposed persons and assets can be reduced, the only feasible way to implement DRR is reducing vulnerability, increasing an exposed population's awareness of natural events (prevention) and reducing their burden of suffering from adverse effects when impacted by an event (mitigation). Beyond technical and economic innovations, this process calls for various public and private interventions to enhance the role of local communities and institutions in designing tailor-made solutions.

If local communities must represent the core of systemic actions needed to reduce vulnerability and to activate processes of technical, economic, and social innovation (Pagliacci et al., 2017), local heterogeneity is expected to matter, both in outlining the analytical framework to prioritize interventions and in implementing policy measures on mitigation and building back better. Unfortunately, economic literature has too often neglected - or misconsidered - the issue of the territorial implementation of general policies. The same holds true for local governments, which focus only on their own single territories (Fuchs et al., 2017). So far, literature has mainly focused on the nationwide level of interventions. Only recently, in designing tools to implement the Sendai Framework's indications for disaster risk reduction (UNISDR, 2015), the attention has shifted to subnational levels, with a focus on large cities (UNISDR, 2017), while other contributions focus on isolated communities (Shaw et al., 2018) and mountain areas (Zimmermann and Keiler, 2015; Klein et al. 2019), which are subject to multi-hazard and increasingly vulnerable to extreme events and climate change.

To address the issue of local heterogeneity, a complementary perspective should consider that both local-level vulnerability and the variety of socio-economic conditions across neighbouring territories matter. Moreover, what also matters is quality of institutions, which

\footnotetext{
${ }^{8}$ We wish to thank an anonymous referee for stressing the fact that is preferable to apply the concept of risk in relative than in absolute way.
}

may differ also within a single country ${ }^{9}$, and the coherence of the various policy objectives ${ }^{10}$.

Thus, in order to build an analytical framework for DRR, a solid and shared knowledge-base on hazards at local level is a necessary - but not sufficient - condition to improve prevention and mitigation ${ }^{11}$. In fact, it should couple with the identification of local levels of exposure and vulnerability, which is also driven by socioeconomic characteristics of places. For example, when considering preparedness interventions, large cities are expected to behave and perform differently from rural or remote regions. Thus, it is clear that the analysis calls for a proper assessment of the territorial heterogeneity under many dimensions. In Italy, this has always represented a widely debated topic. Italian postWWII socioeconomic literature stressed the North-South divide, and later the changed conditions that emerged in the 1970s highlighted the emergence of the so-called 'Third Italy' (Bagnasco, 1977). More recently, new territorial imbalances have been analysed across Italy. For instance, Bertolini et al. (2008) stress the urban-rural divides in terms of socioeconomic performances. In particular, rural areas have suffered from socioeconomic weakness and negative demographic trends since the mass urbanization process (Copus et al., 2015), which today make them more vulnerable also to adverse natural events. The National Strategy for Inner Areas has also assessed this issue (Barca et al., 2014). The strategy identifies 'inner areas' as those municipalities located far away from those cities providing essential services. Actually, it only considers availability of services and geographical distance from them. According to the methodology implemented by Barca et al. (2014), Italian municipalities are classified into six types: A. poles; B. intermunicipality poles; C. belt; D. intermediate; E. peripheral; F. ultraperipheral areas (for further details, refer to Barca et al., 2014). It should be noticed that poor connections with neighbours (as it happens in the case of inner areas) not only negatively affect the generalised vulnerability to economic shocks (Barca et al., 2014), they also represent key components of vulnerability, with regard to adverse natural events.

In this perspective, the issue of scale - at the core of the definition of indicators of vulnerability - is complemented by the classification returned by the National Strategy for Inner Areas, as a background for the analysis of the geographical and spatial relationships encompassing neighbouring territories as well.

\section{The case study: which role for neighbouring space?}

\subsection{Italy: a country prone to adverse natural events}

Italy is prone to natural hazards, also due to its geographical location (Valensise et al., 2017), and it has suffered a long history of catastrophic events. Nevertheless, only the dramatic earthquake events of 2016 in Central Italy (causing more than 300 human losses and considerable damage to the economic, productive, artistic and social fabric) have brought back to the centre of general attention the importance of implementing national and local actions to reduce risks (Pagliacci and Russo, 2019a).

The launch of the "Casa Italia" Plan - an extraordinary measure promoted by the Italian Government, in line with the priorities of the Sendai Framework (UNISDR, 2015) - represents a "comprehensive proposal aimed at protecting Italy's public buildings, homes and cultural sites over the next decades" (Pagliacci et al., 2017, p. 92). This plan stresses the

\footnotetext{
${ }^{9}$ See Barone and Mocetti (2014) for a comparative analysis of Italian earthquakes, occurring in different regions over the last 40 years.

${ }^{10}$ See Fuchs et al. (2017) for an empirical analysis of the impact of policy objectives and interventions in Austria with regard to financial support to building in hazard prone areas.

${ }^{11}$ That perspective is the one adopted by Modica and Zoboli (2016) and by Marin et al. (2019).
} 
importance of implementing 'building back better' actions and building safer buildings (Esposito et al., 2017). Moving from the need for risk assessment, the "Casa Italia" Plan has also encouraged the creation of an integrated information framework on the main hazards in Italy. Thus, in August 2017, Istat (the Italian National Institute for Statistics) made available a dataset on hazards from earthquakes, volcanic eruptions, landslides and floods, on a municipality basis. In fact, information at municipality level is crucial to highlight local heterogeneity, and to strengthen the capacity of exposed local governments and communities to reduce their vulnerability (Russo and Silvestri, 2017).

\subsection{Territorial heterogeneity and spatial effects: a tale of two cities}

To illustrate that the vulnerability of each municipality's neighbours plays a role, let's imagine that an adverse natural event with the same characteristics hits two municipalities with similar socioeconomic features that characterise their vulnerability: both of them are rural communities, with a limited presence of manufacturing activities, with a low level of local technical skills, and lacking essential governance competences, because of their small size. Let's also imagine that these municipalities also share similar hazard levels (and types), so policymakers and local communities should be similarly aware of what could happen. Given these hypothetical conditions, the literature (e.g. UNDRO, 1980) would suggest that both municipalities should face a similar (i.e. large) disaster risk in the case of an adverse event, because of similar vulnerability. Let's now introduce, as a major difference between the two municipalities, the characteristics of their neighbours: one municipality is embedded in a network of relationships with its neighbouring municipalities (with whom has already experienced durable practices of shared common functions and services); the other one is surrounded only by other remote and vulnerable local communities. If this were the case, would these two municipalities experience similar effects after the occurrence of an adverse natural event? Perhaps, no one would say a yes. Everyone would say that the former municipality could take advantage, both in the aftermath and in the reconstruction process, of its embeddedness in the network of municipalities, on which it could leverage for compensating on shortage of tangible and intangible assets, that could be made accessible both for households and for economic agents, hit by the event.

\section{Data and methodology}

Since the 1990s, many works have adopted a territorial approach in dealing with place-based social vulnerability, tackling the problems of measuring risks, local resilience and social vulnerability to natural hazards (Briguglio, 1995; Cutter et al., 2003; Cardona, 2005; Cutter and Finch, 2008; Beccari, 2016; Frigerio and De Amicis, 2016, Valensise et al., 2017). ${ }^{12}$ Nevertheless, most of them have ignored spatial interrelationships and the role for neighbouring territories in mitigating the socioeconomic impact of natural hazard. In fact, only with regard to the USA, Cutter and Finch (2008) assess social vulnerability to natural hazards at county level, encompassing spatial autocorrelation. They develop a Social Vulnerability Index (SoVI) grounded on the underlying socioeconomic and demographic profile of US counties. Then they determine patterns of similarity and dissimilarity in the way the SoVI clusters across the USA, examining its spatial autocorrelation through Global Moran's I (Moran, 1950) and local indicator of spatial autocorrelation (LISA or the Local Moran's I) (Anselin, 1995). As far as the Italian case is concerned, not even the detailed and well-informed paper by Marin et al. (2019) explicitly encompasses the issue of neighbourhood. Aiming at filling this gap, the present work suggests to refer to Exploratory Spatial Data Analysis (ESDA), hence adopting the approach suggested by Cutter and Finch (2008), despite a lower variety of socioeconomic data in the case of Italy.

\footnotetext{
${ }^{12}$ For an exhaustive literature review on this topic, see Cutter et al. (2014).
}

After the description of data, this section presents the methodological choices of the ESDA approach suggested here.

\subsection{Assessing hazard, exposure and vulnerability: data}

This paper builds on the results of Pagliacci and Russo (2019a) who compute a multi-hazard indicator (MHI) at municipality level, to assess hazard across Italy, by considering earthquake, landslide, and flood hazard (7983 observations in total, according to the 2016 administrative partition) ${ }^{13}$. In accordance with the UN definition (Cardona, 2005), Pagliacci and Russo (2019a) also provide figures on exposure of Italian municipalities ${ }^{14}$.

With regard to social vulnerability, several approaches can be adopted. For the USA, Cutter and Finch (2008) computed an indicator of social vulnerability (i.e., the SoVI), starting from a set of 42 socioeconomic variables they had collected from U.S. Census sources at county level. Applying a principal components analysis, they extracted key dimensions of social vulnerability, then computing a comprehensive SoVI score, by summing all of the independent component loadings. With regard to Italy, Marin et al. (2019) adopted a different approach: they computed an indicator of local vulnerability, moving from a systematic review of the available indicators, so to limit the arbitrariness of the process. Then, according to the number of times each attribute occurred in the literature, they calculated a weighted synthetic indicator ${ }^{15}$.

As already done by Pagliacci and Russo (2019a), also the present work relies on the indicator of social vulnerability made available by the Italian National Institute of Statistics: the Index of Social and Material Vulnerability (ISMV), which provides a synthetic measure of the level of social and material vulnerability for each Italian municipality ${ }^{16}$ (Istat, 2018). For the purpose of this work, ISMV is actually a simpler indicator than the one proposed by Marin et al. $(2019)^{17}$, and it is available with no need for further elaborations.

As a main summary, Table 1 comprises all the main input variables used to assess hazard, exposure, and vulnerability, specifying the statistical sources.

\footnotetext{
${ }^{13}$ As input variables, Pagliacci and Russo (2019a) consider maximum Peak Ground Acceleration, or PGA (as a proxy for earthquake hazard), the share of the municipality area under landslide hazard, and the share of the municipality area under flood hazard. To assess multi-hazard, these inputs are combined according to a twofold strategy. First, a hierarchical cluster analysis (Kaufman and Rousseeuw, 1990) returns seven different clusters, labelled as follows: No hazard; Medium hazard: earthquakes; Medium hazard: floods; Medium hazard: earthquakes \& landslides; High hazard: earthquakes; High hazard: earthquakes \& landslides; High hazard: floods. Second, and in order to rank these clusters, a synthetic Multi-Hazard Indicator (MHI) is computed, by taking the average of inputs' normalised squares (here inputs are the same used for cluster analysis). Data can be freely accessed online at http://hdl.handle.net/11380/1184020.

${ }^{14}$ With regard to exposure, the following set of raw data is considered: total population (year 2015); number of residential buildings (year 2011); total employment (year 2015); total employment in manufacturing activities (Section C of the NACE Rev. 2) (year 2015); agricultural holdings with utilised agricultural area (year 2010). For the whole set of variables, the data source is Istat (http://dati.istat.it).

${ }^{15}$ The authors claim they have only selected those variables that had appeared in the literature at least 15\% of the times (Marin et al., 2019).

${ }^{16}$ This indicator combines seven elementary indicators referring to key socioeconomic conditions: i) \% of illiterate population (25-64 years old); ii) \% of households with 6 and more components; iii) \% of single parent families; iv) \% of households with potential hardship, to indicate the share of families only composed of elderly people (65 years and older) with at least one 80-year-old component; v) \% of the population in condition of serious crowding, given by the dwelling surface/inhabitants ratio; vi) \% of NEET young people (15-29 years old); vii) $\%$ of households with potential economic disadvantage, indicating the share of families with children in which all members are unemployed, or have withdrawn from work (Istat, 2018).

${ }^{17}$ In particular, the set of weights deriving from the method by Marin et al. (2019) are not freely available.
} 
Table 1

Input variables for hazard, exposure, and vulnerability.

\begin{tabular}{|c|c|c|}
\hline Variable & Description & Source \\
\hline \multicolumn{3}{|l|}{ HAZARD } \\
\hline Earthquake & Normalised Peak Ground Acceleration & $\begin{array}{l}\text { Pagliacci and Russo (2019a) on Civil } \\
\text { Protection (2015) data }\end{array}$ \\
\hline Landslide & $\begin{array}{l}\text { Normalised share of at-risk areas, considering P4 (very high), P3 (high), and PAA } \\
\text { (areas of attention) areas for landslides }\end{array}$ & $\begin{array}{l}\text { Pagliacci and Russo (2019a) on CNR-IRPI } \\
\text { (2015) data }\end{array}$ \\
\hline Flood & $\begin{array}{l}\text { Normalised share of at-risk areas, considering the widest area comparing P1 low- } \\
\text { hazard scenario and P2 medium-hazard scenario }\end{array}$ & $\begin{array}{l}\text { Pagliacci and Russo (2019a) on CNR-IRPI } \\
\text { (2015) data }\end{array}$ \\
\hline Multi hazard index (MHI) & $\begin{array}{l}\text { The average of the normalised squares of the three aforementioned hazard } \\
\text { indicators }\end{array}$ & Pagliacci and Russo (2019a) \\
\hline \multicolumn{3}{|l|}{ EXPOSURE } \\
\hline Total population & Total population (in 2015) & Istat (http://dati.istat.it) \\
\hline Residential buildings & Number of residential buildings (in 2011) & General Census Istat (http://dati.istat.it) \\
\hline Total employment & Total employment - all economic sectors (in 2015) & Istat (http://dati.istat.it) \\
\hline Employment in manufacturing & Total employment in manufacturing activities (NACE Rev. 2, Section C) (in 2015) & Istat (http://dati.istat.it) \\
\hline Agricultural holdings with UAA & Agricultural holdings with utilised agricultural area (UAA) in 2010 & General Census Istat (http://dati.istat.it) \\
\hline \multicolumn{3}{|l|}{ VULNERABILITY } \\
\hline $\begin{array}{l}\text { Index of Social and Material Vulnerability } \\
\text { (ISMV) }\end{array}$ & $\begin{array}{l}\text { A synthetic measure of the level of social and material vulnerability for Italian } \\
\text { municipalities }\end{array}$ & Istat (2018) \\
\hline
\end{tabular}

Multi hazard

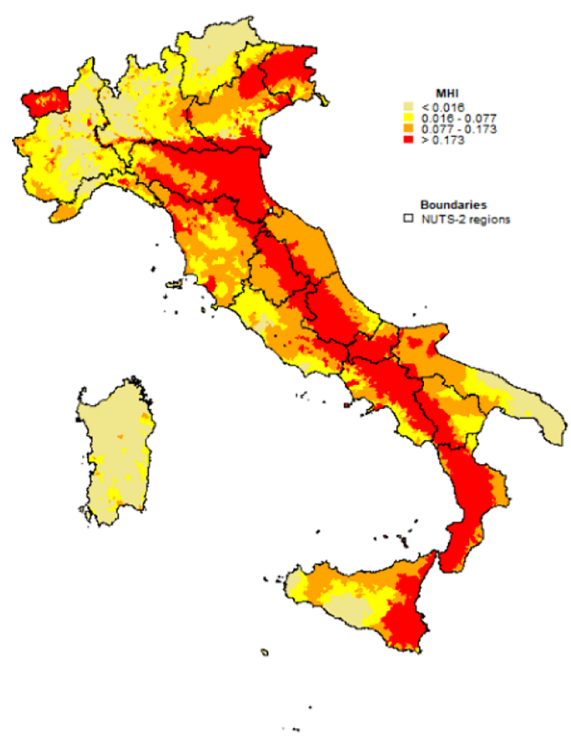

Exposure

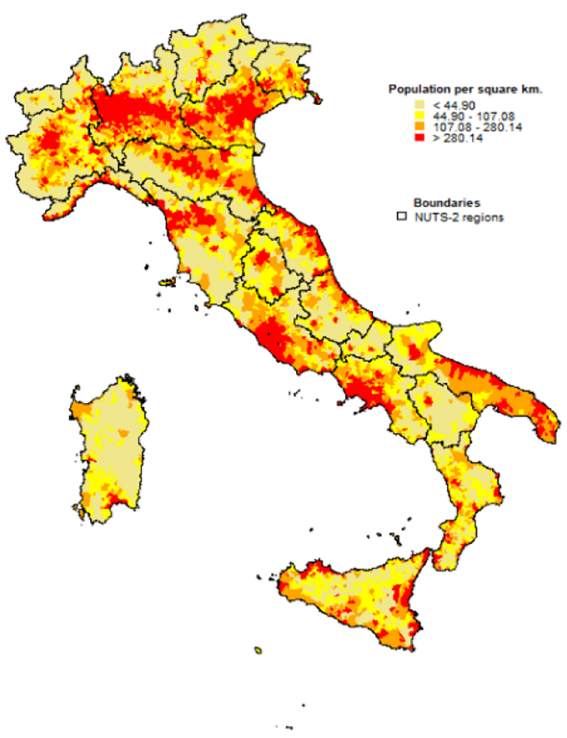

Vulnerability

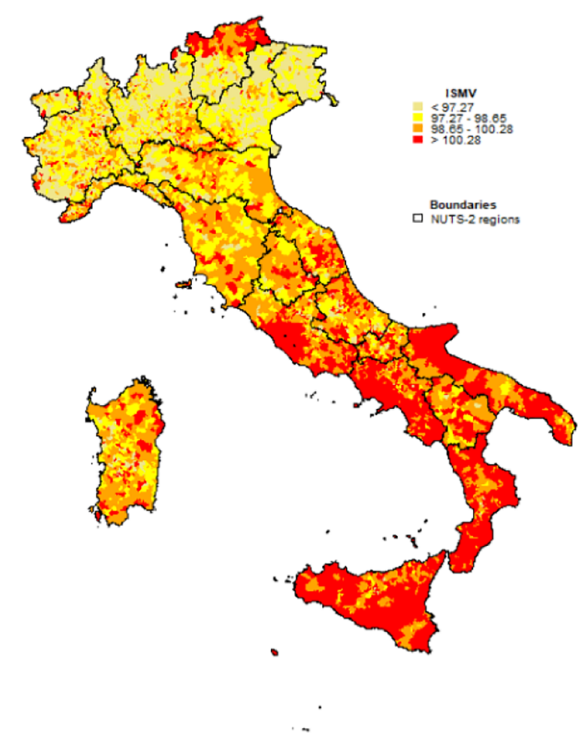

Fig. 1. Hazard, exposure, and vulnerability throughout Italy. Source: author's elaboration on Pagliacci and Russo (2019a).

Fig. 1 maps multi-hazard (MHI) ${ }^{18}$, exposure (population per square kilometre), and vulnerability (ISMV by Istat), throughout Italy. Each map shows the distribution of municipalities by quartile. It is worth highlighting some considerations about the geographic pattern of each dimension. High MHI values occur across Central and Southern Italy (especially along the Apennines), while municipalities in the NorthWest and in Sardinia share low MHI values ${ }^{19}$. As far as exposure is

\footnotetext{
${ }^{18}$ Refer to Pagliacci and Russo (2019a) for the results of the cluster analysis.

${ }^{19}$ Due to the fact the Italian municipalities largely differ in terms of their own surface, the maps in Fig. 1 could appear misleading. In fact, although each class (i.e., quartile) includes the same number of municipalities, the most hazardous class covers a surface area which is almost twice as large as the one covered by the least hazardous quartile $\left(91,390 \mathrm{~km}^{2}\right.$ and $58,582 \mathrm{~km}^{2}$, respectively). Data on population are similarly insightful. In 2015, less than $26 \mathrm{~m}$ inhabitants lived in the municipalities belonging to the two least hazardous quartiles, while about $35 \mathrm{~m}$ inhabitants lived in the municipalities belonging to the two most hazardous quartiles.
}

concerned, its geographic pattern follows more traditional divides, between flatlands (in the North) and coastal areas on the one hand, and mountain areas on the other. Large urban areas are those where exposure is the largest one, with regard to all aspects of economic activity. Lastly, with regard to social and material vulnerability, the geographic pattern of the ISMV returns the well consolidated North-South divide: Southern municipalities are among the most vulnerable ones, and both large cities and rural municipalities share similar values.

More generally, it can be noticed that, whereas hazards follow an inherently spatial distribution, patterns of spatial association for both exposure and vulnerability tend to be more blurred. Thus, specific statistical methodologies have been implemented to assess their features at neighbourhood level. In any case, it is clear that neighbouring places matter. Either being a single remote municipality or having only other remote municipalities as neighbours may represent additional sources of vulnerability. 


\subsection{Modelling the neighbouring space}

To measure the degree of dependency among observations in a given geographic space, Exploratory Spatial Data Analysis (ESDA) can be adopted (Anselin, 1988; Bivand et al., 2008). Here, ESDA is applied to the main variables describing exposure and vulnerability: according to Moran (1950) and Cliff and Ord (1981), global Moran's I statistic tests for the presence of spatial dependence, by considering a $(n \times n)$ row-standardized spatial weights matrix (W), whose generic element $\mathrm{w}_{\mathrm{ij}}$ is defined as follows:

$w_{i j}=\frac{w_{i j}^{*}}{\sum_{j=1}^{M} w_{i j}^{*}}$

where $w_{i j}^{*}$ can take two different values. It is equal to 1 , when $i \neq j$ and $j \in N(i)$. It is equal to 0 , when $i=j$ or when $i \neq j$ and $j \notin N(i)$. Here, $\mathrm{N}$ (i) represents the set of neighbours of the $i$-th region $(i=1, \ldots, M)$. Here $N(i)$, hence $\mathbf{W}$, is defined according to two alternative matrices: a first-order queen contiguity matrix and a 5-nearest (according to centroid location) neighbour contiguity matrix. In the former cases, island municipalities (14 in Italy ${ }^{20}$ ) have no neighbours. In the latter case, the matrix of neighbours is asymmetric, but it ensures that all municipalities have the same number of neighbours (Bivand et al., 2008).

Secondly, bivariate ESDA is applied as well. By referring to the same spatial weight matrices (W), also the correlation between multi-hazard, on the one hand, and spatially-lagged exposure and spatially-lagged vulnerability is assessed. Such a bivariate analysis is actually intended to test the main characteristics of the neighbouring municipalities to be accessed, in the case of an adverse natural event.

\section{Results: the neighbouring space}

The neighbouring space of Italian municipalities is returned by the spatial matrices mentioned above. When using the first-order queen contiguity matrix, Italian municipalities show 5.9 neighbours, on average, despite a large variance among observations (Table 2). As expected, the number of neighbours vary according to the municipality type, in terms of inner areas as defined by the National Strategy (Barca et al., 2014). While municipalities with a lower number of neighbours mostly occur among inner areas, poles and inter-municipality poles usually show a larger number of neighbours.

According to both contiguity matrices, global Moran's I are returned with regard to exposure and vulnerability (Table 3). Due to the fact that Italian municipalities largely differ in terms of their territorial area, exposure indicators have been considered in relative terms, by taking their respective data per square kilometre.

As shown in Table 3, Moran's I is always significant for both exposure variables and for the indicator of local vulnerability (ISMV), no matter which contiguity matrix is adopted. ${ }^{21}$ This finding indicates that - on average, at the national level - each of the aforementioned variables shows a clear tendency to clustering. As both exposure and vulnerability affect risks (UNDRO, 1980), effects of an adverse natural event tend to amplify in neighbouring space. Actually, high-exposure municipalities are located close to other high-exposure municipalities, and high-vulnerability municipalities are located close to other highvulnerability municipalities. Referring to the latest issue, a companion analysis grounded on the application of the Local Moran's I (LISA) (Anselin, 1995) strengthens this finding. LISA captures the local variability of the ISMV, hence allowing the identification of spatial clusters of municipalities with similar values (high-high and low-low) as well as the existence of spatial outliers, namely high-vulnerability (or low-vulnerability) municipalities, whose neighbours show low (or high) vulnerability. This latter analysis shows that the vulnerable

\footnotetext{
${ }^{20}$ Detailed list is available upon request.

${ }^{21}$ Moran scatterplots are also available, upon request.
}

municipalities with vulnerable neighbours (high-high case) are 726, accounting for $23.0 \%$ of Italian population (13.97 million people $)^{22}$. Among them, there is also the city of Rome. Even disregarding the capital city, the high-high cases still represent $19.2 \%$ of the total Italian population. Less vulnerable municipalities with less vulnerable neighbours (low-low cases), representing $1.1 \%$ of total population, mostly occur across Northern Italy, in rural and mountain areas. They are 294 municipalities, with a tiny average population (2344 inhabitants).

However, more insightful results emerge when considering correlation coefficients among different variables of hazard, exposure, and vulnerability, on the one hand, and spatially-lagged variables on the other. In this regard, Table 4 returns the Pearson correlation coefficient among single hazards and the MHI, on the one hand, and spatiallylagged exposure and spatially-lagged vulnerability, on the other. Data suggests that MHI is positively correlated to spatially-lagged residential buildings, and agricultural holdings, while it is negatively correlated to total employment. Moreover, higher levels of MHI also correlate with higher levels of spatially-lagged ISMV: this means that, in those cases, no benefit is likely to derive from the neighbours ${ }^{23}$. When distinguishing by type of hazard, the main findings - already suggested in the literature - appear to be confirmed, such as the fact the floods tend to associate with less vulnerable areas as well as less vulnerable neighbours (Pagliacci, 2017).

\section{Discussion and policy implications}

The analysis presented in this paper sheds new light on the implementation of DRR policies at a local level, asking for the proper awareness, in policy design, of the implications of the combined territorial distributions of multi-hazard, exposure and vulnerability. One result of the paper is that interventions should be implemented not only at municipality-level, but also encompassing neighbouring areas, which are likely to share socioeconomic relationships (embedded in people relationships, in local portions of value chains, in face-to-face business interactions) and institutional settings.

Focusing on the neighbouring space allows the identification of a very significant set of areas of interventions: municipalities with high multi-hazard index, with high socioeconomic and material vulnerability of themselves and of their neighbourhood should be at the top of a list of urgent interventions to be undertaken. Fig. 2 maps the results of this combination, returning a set of 308 municipalities in Italy, mostly in Southern regions, which comprehensively account for almost 3 million inhabitants. One third of that population is concentrated in eight "poles" (according to the National Strategy for Inner Areas classification), i.e. they are at the core of services (from education to health, justice, transport, utilities) for their neighbourhood: a disaster occurring in one of those municipalities would then have an even greater impact also on the surroundings, even if its neighbours were not directly affected. The remaining municipalities in the top list of urgent interventions have opposite characteristics (Table 5 and Fig. 3): they mostly have very small size (ranging from an average of 2,000 inhabitants to about 9,000) and in case of disaster this would largely question the future of the population in their original settings, because of the general long-term need to recover, the complexity of interventions in rural and mountain areas, as those specific cases. In conclusion, focusing on the vulnerability of the neighbouring space allows to

\footnotetext{
${ }^{22}$ These results are obtained by assessing neighbourhood by means of the first-order queen contiguity matrix. However, analogous results can be obtained by means of the 5-nearest neighbours matrix. All results are available upon request.

${ }^{23}$ The analysis of the characteristics of the spatial clusters (obtained by the application of the LISA indicator) confirms this finding. The average value of the MHI for the spatial clusters of high-high vulnerability municipalities is 0.163 , while it is 0.061 for the spatial clusters of low-low vulnerability municipalities.
} 
Table 2

Italian municipalities, by number of neighbours and type of inner areas.

\begin{tabular}{|c|c|c|c|c|c|c|c|}
\hline No. Neighbours & No. Municipalities & A poles & B inter-municipality poles & $\mathrm{C}$ belt & D intermediate & E Peripheral & F Ultra-peripheral \\
\hline 0 & 14 & & & & 1 & 12 & 1 \\
\hline 1 & 23 & & 1 & 4 & 6 & 9 & 3 \\
\hline 2 & 135 & & & 48 & 39 & 44 & 4 \\
\hline 3 & 508 & 7 & 8 & 209 & 142 & 120 & 22 \\
\hline 4 & 1261 & 14 & 9 & 604 & 354 & 237 & 43 \\
\hline 5 & 1798 & 10 & 22 & 884 & 514 & 309 & 59 \\
\hline 6 & 1702 & 16 & 29 & 778 & 522 & 294 & 63 \\
\hline 7 & 1169 & 33 & 23 & 526 & 337 & 211 & 39 \\
\hline 8 & 634 & 28 & 7 & 250 & 199 & 121 & 29 \\
\hline 9 & 349 & 23 & 7 & 133 & 105 & 62 & 19 \\
\hline 10 & 168 & 13 & 7 & 53 & 53 & 38 & 4 \\
\hline 11 & 88 & 16 & 4 & 23 & 28 & 16 & 1 \\
\hline 12 & 52 & 20 & 1 & 14 & 7 & 7 & 3 \\
\hline 13 & 33 & 8 & 3 & 6 & 6 & 9 & 1 \\
\hline 14 & 19 & 9 & & & 4 & 4 & 2 \\
\hline 15 & 6 & 5 & & 1 & & & \\
\hline 16 & 5 & 4 & & 1 & & & \\
\hline 17 & 8 & 4 & 1 & 2 & & 1 & \\
\hline 18 & 3 & 1 & & & & 2 & \\
\hline 19 & 2 & 2 & & & & & \\
\hline 21 & 3 & 2 & & 1 & & & \\
\hline 23 & 2 & 1 & & 1 & & & \\
\hline \multirow[t]{2}{*}{29} & 1 & 1 & & & & & \\
\hline & 7983 & 217 & 122 & 3538 & 2317 & 1496 & 293 \\
\hline
\end{tabular}

Source: authors' elaboration on Istat data.

Table 3

Moran's I values for exposure and vulnerability variables.

\begin{tabular}{llll}
\hline Variable & Moran's I & & \\
\cline { 3 - 4 } & First-order queen contiguity & & \\
\hline Exposure & & & \\
Total population & 0.736 & $* * *$ & 0.729 \\
Residential buildings & 0.653 & $* * *$ & 0.714 \\
Total employment & 0.722 & $* * * *$ & 0.629 \\
Employment in manufacturing & 0.607 & $* * *$ & 0.652 \\
Agricultural holdings with UAA & 0.740 & & 0.793 \\
Vulnerability & & $* * * *$ & $* *$ \\
ISMV & 0.642 & $* * *$ & 0.651 \\
\hline
\end{tabular}

Legend: $* * *$ statistically significant at $0.1 \%$.

Source: authors' elaboration on Istat data.

Table 4

Pearson correlation coefficients of hazard vs lagged exposure and vulnerability.

\begin{tabular}{|c|c|c|c|c|c|c|}
\hline \multirow[t]{2}{*}{ Hazard } & \multicolumn{5}{|l|}{ Lagged exposure } & \multirow{2}{*}{$\begin{array}{l}\text { Lagged vulnerability } \\
\text { Index of social and material } \\
\text { vulnerability (ISMV) }\end{array}$} \\
\hline & Total population & $\begin{array}{l}\text { Residential } \\
\text { buildings }\end{array}$ & Total employment & $\begin{array}{l}\text { Employment in } \\
\text { manufacturing }\end{array}$ & $\begin{array}{l}\text { Agricultural holdings with } \\
\text { utilised agricultural area (UAA) }\end{array}$ & \\
\hline \multirow{2}{*}{$\begin{array}{l}\text { Multi hazard index } \\
\text { (MHI) }\end{array}$} & -0.017 & $0.053^{* * *}$ & -0.028 & 0.007 & $0.085^{* * *}$ & $0.140^{* * *}$ \\
\hline & $(0.131)$ & $(0.000)$ & $(0.011)$ & $(0.556)$ & $(0.000)$ & $(0.000)$ \\
\hline Earthquake & $\begin{array}{l}0.004 \\
(0.719)\end{array}$ & $\begin{array}{l}0.080 * * * \\
(0.000)\end{array}$ & $\begin{array}{l}-0.023 \\
(0.036)\end{array}$ & $\begin{array}{l}-0.025 \\
(0.024)\end{array}$ & $\begin{array}{l}0.172^{* * *} \\
(0.000)\end{array}$ & $\begin{array}{l}0.199 * * * \\
(0.000)\end{array}$ \\
\hline Landslide & $\begin{array}{l}-0.064^{* * *} \\
(0.000)\end{array}$ & $\begin{array}{l}-0.104^{* * *} \\
(0.000)\end{array}$ & $\begin{array}{l}-0.062^{* * *} \\
(0.000)\end{array}$ & $\begin{array}{l}-0.124^{* * *} \\
(0.000)\end{array}$ & $\begin{array}{l}-0.048^{* * *} \\
(0.000)\end{array}$ & $\begin{array}{l}0.051^{* * *} \\
(0.000)\end{array}$ \\
\hline Flood & $\begin{array}{l}0.014 \\
(0.204)\end{array}$ & $\begin{array}{l}0.059 * * * \\
(0.000)\end{array}$ & $\begin{array}{l}0.025 \\
(0.025)\end{array}$ & $\begin{array}{l}0.151^{* * *} \\
(0.000)\end{array}$ & $\begin{array}{l}-0.043^{* * *} \\
(0.000)\end{array}$ & $\begin{array}{l}-0.045^{* * *} \\
(0.000)\end{array}$ \\
\hline
\end{tabular}

Legend: $* * *$ statistically significant at $0.1 \%$.

Source: authors' elaboration on Istat data. 


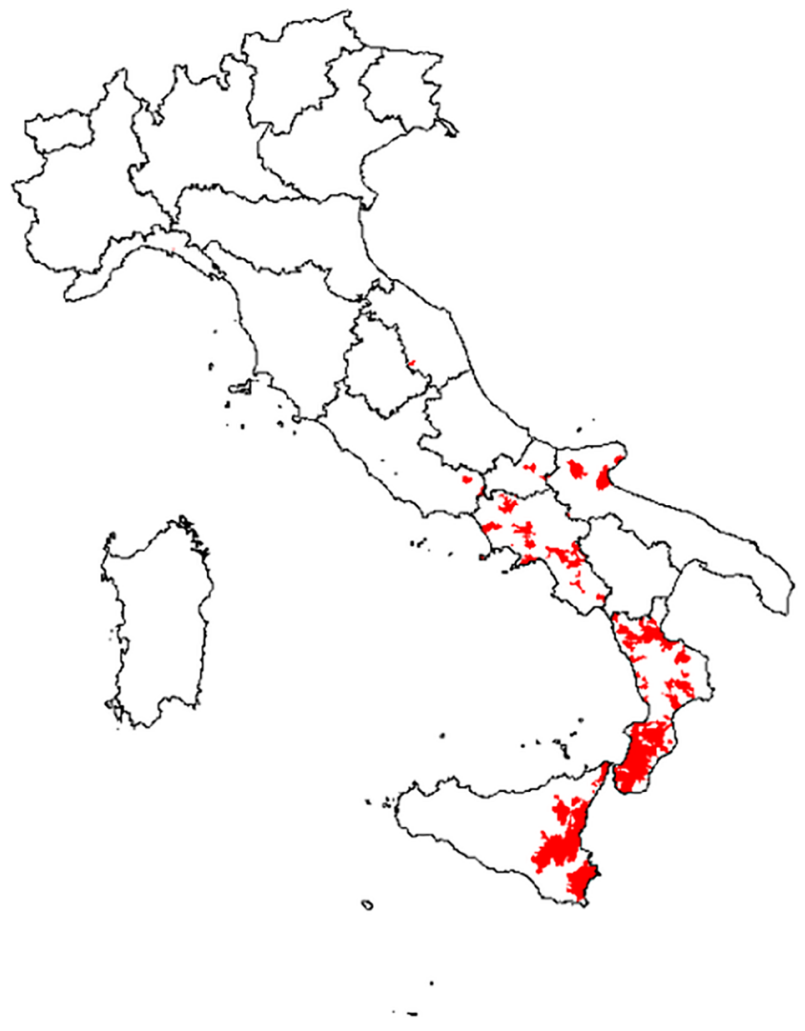

Fig. 2. Municipalities with high MHI (1st quartile), in the high-high vulnerability cases Source: Authors' elaboration.

Table 5

Municipalities with high MHI (1st quartile), in the high-high vulnerability cases: number and population, by inner area type.

\begin{tabular}{lrr}
\hline & No. municip. & Population \\
\hline A Poles & 8 & $1,068,307$ \\
B Inter-municipality poles & 4 & 83,518 \\
C Belt & 80 & 709,056 \\
D Intermediate & 108 & 661,394 \\
E Peripheral & 98 & 440,506 \\
F Ultra-peripheral & 10 & 20,402 \\
Total & 308 & $2,983,183$
\end{tabular}

Source: Authors' elaboration.

highlight the need for different types of interventions, although all of them are urgent ${ }^{24}$.

The neighbouring perspective need to define local units of analysis, an issue well known in the economic debate on local development and regional innovation systems (Perroux, 1987; Hirschman, 1958, 1967; Brusco, 1982; Russo, 1996; Becattini et al., 2009): the analytical framework presented in this paper highlights the specific need for defining the territorial unit of policy intervention. Due to the fact that the occurrence of each specific hazard is spatially-driven - and often locallydelimited - national-level intervention plans should assess local-level exposure and local-level vulnerability as well as their interplay, which could dramatically affect the outcome of an event, hence risk. This is the reason why nation-level DRR implementation policies are rarely effective, even in developed countries.

Taking Italy as an example, there is no doubt that the country as a whole is prone to natural multi-hazards, thus, it would largely benefit

\footnotetext{
${ }^{24}$ It should be considered that, following Füssel (2007), different dimensions of vulnerability have implications for different types of policies, in terms of hazard mitigation, adaption and compensation.
}

from urgent interventions, demanding huge amount of resources (both private and public), spanning a long-term period.

To become effective, the long-term plans have to prioritize interventions. After the collective emotion spurred by the tragic consequences of a disaster, any national-scale prevention plans should take specific local conditions into account. In this respect, let us consider the "Casa Italia" Plan, which will eventually target the whole country. In its implementation, it builds on ten pilot municipalities ${ }^{25}$, which encompass both large cities (Catania and Reggio di Calabria, both with more than 100,000 inhabitants) and smaller rural municipalities (e.g. Sora and Piedimonte Matese, in the Southern Apennines). These pilots represent an opportunity to address also the creation (or the consolidation) of stronger interrelationships across their neighbouring space.

In the local implementation of these nation-wide interventions, policy makers would largely benefit from specific knowledge of the "more socially vulnerable zones against hazards, in order to identify appropriate cost-effective risk reduction strategies to be implemented at national and at the local level" (Frigerio and De Amicis, 2016, p. 194). This is exactly in line with the UNISDR's (2015) suggestions for enhancing local and community-level preparedness, for instance in the implementation of specific risk mitigation measures. Moreover, also Civil Protection could largely benefit from such a tool, during "pre and post-disaster activities such as communication of emergency procedure" (Frigerio and De Amicis, 2016, p. 195). In particular, the creation of multi-hazard territorial authorities - acting at inter-municipality level - could support Italian municipalities to integrate systemic plans to implement effective preparedness at local level (Marin et al., 2019; Pagliacci and Russo, 2019a).

Clearly, these interventions call for a more general questioning of the spatial granularity of available information on hazard, exposure, and vulnerability. Too often information is not consistent with the available data on population, economic activities and social infrastructures. Taking municipality-level average data per square kilometre might create distortions in the combined effects of multi-hazards, which could be more sensitive at the sub-municipality scale. Hence, a preliminary effort should be the alignment of the spatial granularity of different pieces of information, which are the inputs for any econometric analysis to support informed policy measures.

The effectiveness of such policies is specifically relevant when the extent of exposed assets is extremely large and then the setting of priorities is crucial. In Italy, medium-high hazard municipalities account for $65 \%$ of people and residential buildings. Such a large scale of intervention needs decades to be realised, a huge amount of available private and public resources, and the creation of specific technical and administrative competences. Econometric models returning a set of priorities would help in orienting the path of interventions.

The process of change, triggered by these interventions, cannot be maintained without enhancing local communities' awareness, also embracing a relational perspective across communities. And to some extent, it is also desirable, as it could support emulation.

\section{Conclusions}

This paper focuses on the importance of assessing local-level heterogeneity of neighbours, in particular when dealing with the analysis of vulnerability to adverse natural events. In addition to the studies stressing the importance of exposure and vulnerability of local communities living in hazard-prone areas, this paper also singles out the need to address the characteristics of the particular neighbouring space, through indicators based on the ESDA methodology. It is argued that a small municipality surrounded by other remote areas is likely to be

\footnotetext{
${ }^{25}$ They have been preliminary selected (Catania, Feltre, Foligno, Gorizia, Isernia, Piedimonte Matese, Potenza, Reggio di Calabria, Sora and Sulmona).
} 


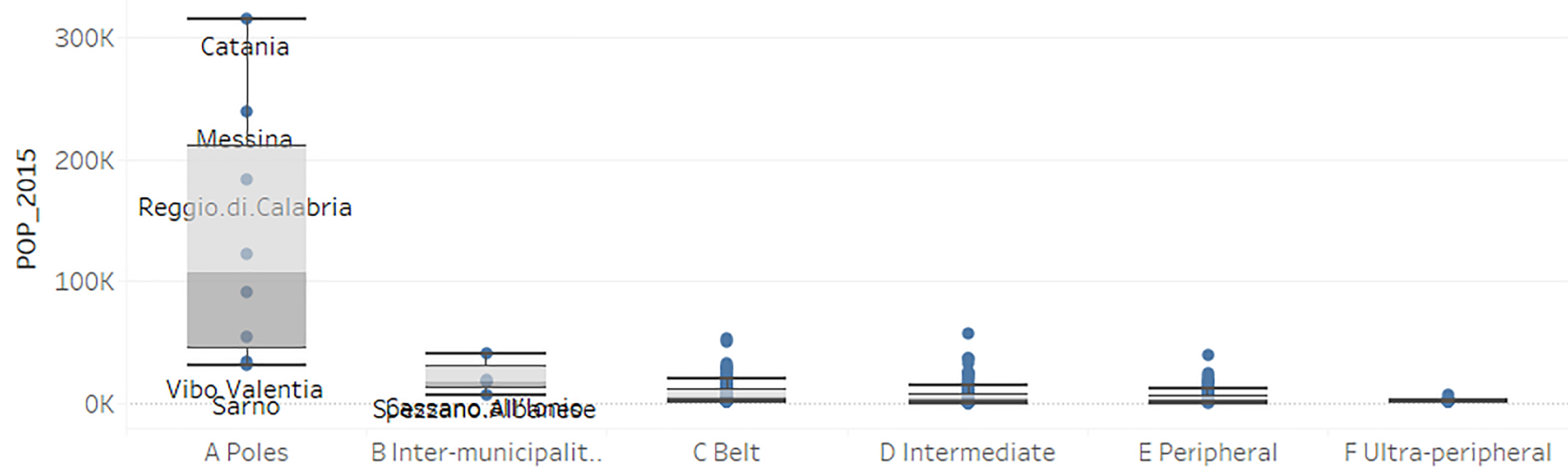

Fig. 3. Box plot of population (2015) in municipalities with high MHI (1st quartile) in the high-high vulnerability cases, by inner area type Source: Authors' elaboration.

much more vulnerable than a similar municipality embedded into a network of relationships with its neighbourhood, endowed with tangible and intangible assets that could support a smoother reaction to an external shock. When considering multi-hazard, exposure, and vulnerability at the municipality level in Italy, a clear tendency to spatial clustering emerges: in fact, high-high and low-low values tend to be spatially associated. Because of the interplay of these features, an adverse natural event is likely to have amplified effects, especially with regard to specific parts of the country.

Provided that relevant data are available, the methodology proposed in this paper, in principle, is applicable to any country facing adverse natural events. With regard to Italy, a more immediate contribution could be made by singling out some outliers, namely some very vulnerable municipalities which could benefit by the presence of less vulnerable neighbours and to target the poles and the small municipalities in the high-high vulnerability cases. To do that, it would be appropriate to broaden the experience acquired from the "Casa Italia" Plan, by considering the neighbours of each pilot. This could contribute to outline the broader socioeconomic processes that are activated by specific interventions on material assets, i.e. the buildings targeted by the Plan. As a result, locked-in paths could be deliberately abandoned: those not having good neighbours yet could benefit from new policies, enhancing those processes that make neighbours behave proactively. The positive impact of greater cooperation among neighbouring municipalities has already been put to the test in the aftermath of the 2012 Emilia earthquake, when also small and rural municipalities benefited from less damaged neighbours, with whom they had already practiced institutional connections.

Beyond the specific pilots of the "Casa Italia" Plan, it should be understood that there is a need for both new sources of data - at a greater spatial granularity - and new and more refined indicators of local vulnerability, encompassing multidimensional information on the neighbouring space to assess the relational embeddedness of communities. These types of data will improve the econometric models that are needed to support more effective policies that, above all, have to set priorities of territorial interventions. Further analyses should not overlook that a plan of interventions has to prioritize places with regard to their relative urgency (because of their high multi-hazard conditions and high vulnerability of places and their neighbourhood), but also with regard to the domains in which there is a scarcity of cooperation practices in the creation of collective goods. Such a lack critically fuels vulnerability.

\section{CRediT authorship contribution statement}

Francesco Pagliacci: Conceptualization, Methodology, Software, Validation, Formal analysis, Data curation, Writing - original draft, Writing - review \& editing, Visualization, Supervision. Margherita
Russo: Conceptualization, Investigation, Resources, Writing - original draft, Writing - review \& editing, Visualization.

\section{Declaration of Competing Interest}

The authors declare that they have no known competing financial interests or personal relationships that could have appeared to influence the work reported in this paper.

\section{Acknowledgment}

The authors wish to thank the Energie Sisma Emilia (www.energie. unimore.it) and the Building Back Better (https:// buildingbackbetterorg.wordpress.com) research teams for the insightful discussions from which this paper largely stemmed. A preliminary version of this paper was presented at the XXXIX Scientific Conference of Associazione Italiana di Scienze Regionali (AISRe) in Bolzano, Italy (17-19 September 2018). The authors would like to thank the discussant and the audience for the useful suggestions received.

The authors also thank the editor and the anonymous referees for their precious suggestions that have led to a great improvement in the overall quality of the paper.

\section{References}

Anselin, L., 1988. Spatial Econometrics: Methods and Models. Springer, Netherlands, Dordrecht.

Anselin, L., 1995. Local indicators of spatial association-LISA. Geographical Anal. 27, 93-115. https://doi.org/10.1111/j.1538-4632.1995.tb00338.x.

Bagnasco, A., 1977. Tre Italie: la problematica territoriale dello sviluppo italiano, Studi e ricerche. Soc. Ed. Il Mulino, Bologna.

Barca, F., Casavola, P., Lucatelli, S., 2014. A strategy for inner areas in Italy: definition, objectives, tools and governance. Materiali Uval Series 31.

Barone, G., Mocetti, S., 2014. Natural disasters, growth and institutions: a tale of two earthquakes. J. Urban Econ. 84, 52-66. https://doi.org/10.1016/j.jue.2014.09.002.

Becattini, G., Bellandi, M., De Propris, L. (Eds.), 2009. A Handbook of industrial districts. Edward Elgar, Cheltenham ; Northampton (MA).

Beccari, B., 2016. A comparative analysis of disaster risk, vulnerability and resilience composite indicators. PLoS Curr. https://doi.org/10.1371/currents.dis. 453df025e34b682e9737f95070f9b970.

Beck, M.W., Shepard, C.C., Birkman, J., Rhyner, J., Witting, M., Wolfertz, J., Martens, J., Maurer, K., Mucke, P., Radtke, K., 2012. World Risk Report 2012: Environmental degradation increases disaster risk worldwide - World. Bündnis Entwicklung Hilft, Bonn.

Bertolini, P., Giovannetti, E., Martinelli, E., Palmirani, M., Pattaro, A.F., Russo, M., Sartori, L., 2016. Analisi degli effetti socio-economici del sisma, in: Unimore e Il Terremoto Del 2012 in Emilia-Romagna. Interventi e Ricerche per Fronteggiare l'emergenza e Sostenere La Ripresa. Carpi, pp. 209-221.

Bertolini, P., Montanari, M., Peragine, V., 2008. Poverty and Social Exclusion in Rural Areas. European Commission, Bruxelles.

Birkmann, J., 2007. Risk and vulnerability indicators at different scales: applicability, usefulness and policy implications. Environ. Hazards 7, 20-31. https://doi.org/10 1016/j.envhaz.2007.04.002.

Bivand, R., Pebesma, E.J., Gómez-Rubio, V., 2008. Applied spatial data analysis with R, New York Heidelberg Dordrecht London. 
Bollin, C., Hidajat, R., 2006. Community-based risk index: Pilot implementation in Indonesia, in: Birkmann, J. (Ed.), Measuring Vulnerability to Natural Hazards-Towards Disaster Resilient Societies. United Nations University, Tokyo ; New York, pp. 383-400.

Bowman, A.O., Parsons, B.M., 2009. Vulnerability and Resilience in Local Government: Assessing the Strength of Performance Regimes. State and Local Briguglio, L., 1995. Small island developing states and their economic vulnerabilities 23, 1615-1632.

Brusco, S., 1982. The Emilian model: productive decentralisation and social integration. Camb. J. Econ. 6, 167-184. https://doi.org/10.1093/oxfordjournals.cje.a035506.

Cardona, O., D., 2005. Indicators of Disaster Risk and Risk Management. Program for Latin America and the Caribbean: Summary Report for World Conference on Disaster Reduction. INTER-AMERICAN DEVELOPMENT BANK Universidad Nacional de Colombia - Sede Manizales Instituto de Estudios Ambientales - IDEA, Manzilas.

Cardona, O., Aalst, M., Birkmann, J., Fordham, M., Mcgregor, G., Perez, R., Pulwarty, R., Schipper, L., Sinh, B., 2012. Determinants of risk: exposure and vulnerability. In: Field, C.B. et al. (Ed.), Managing the Risks of Extreme Events and Disasters to Advance Climate Change Adaptation. Cambridge University Press, Cambridge, UK, and New York, NY, USA, pp. 65-108.

Civil Protection, 2015. Seismic classification. Available at http://www.protezionecivile. gov.it/ jcms/ en/classificazione.wp (latest access: 11 Jan. 2017).

Clarke, S.E., Chenoweth, E., 2006. The politics of vulnerability: constructing local performance regimes for homeland security. Rev. Policy Res. 23, 95-114. https://doi. org /10.1111/j.1541-1338.2006.00187.x.

Cliff, A.D., Ord, J.K., 1981. Spatial Processes: Models \& Applications. Pion, London.

CNR-IRPI, 2015. Rapporto periodico sul rischio posto alla popolazione italiana da frane e inondazioni. Year 2014.

Copus, A., Melo, P.C., Kaup, S., Tagai, G., Artelaris, P., 2015. Regional poverty mapping in Europe - challenges, advances, benefits and limitations. Local Econ. 30, 742-764. https://doi.org/10.1177/0269094215601958.

Costanza, R., Farley, J., 2007. Ecological economics of coastal disasters: introduction to the special issue. Ecol. Econ. 63, 249-253. https://doi.org/10.1016/j.ecolecon.2007. 03.002.

Cutter, S.L., Ash, K.D., Emrich, C.T., 2014. The geographies of community disaster resilience. Global Environ. Change 29, 65-77. https://doi.org/10.1016/j.gloenvcha. 2014.08.005.

Cutter, S.L., Barnes, L., Berry, M., Burton, C., Evans, E., Tate, E., Webb, J., 2008. A placebased model for understanding community resilience to natural disasters. Global Environ. Change 18, 598-606. https://doi.org/10.1016/j.gloenvcha.2008.07.013.

Cutter, S.L., Boruff, B.J., Shirley, W.L., 2003. Social vulnerability to environmental hazards. Social Sci. Q. 84, 242-261. https://doi.org/10.1111/1540-6237.8402002.

Cutter, S.L., Finch, C., 2008. Temporal and spatial changes in social vulnerability to natural hazards. Proc. Natl. Acad. Sci. 105, 2301-2306. https://doi.org/10.1073/ pnas.0710375105.

Dao, Q.-H., Peduzzi, P., 2003. Global Risk And Vulnerability Index Trends per Year (GRAVITY) Phase IV: Annex to WVR and Multi Risk Integration.

Esposito, F., Russo, M., Sargolini, M., Sartori, L., Virgili, V. (Eds.), 2017. Building Back Better: idee e percorsi per la costruzione di comunità resilienti. Carocci-Press online.

Frigerio, I., De Amicis, M., 2016. Mapping social vulnerability to natural hazards in Italy: a suitable tool for risk mitigation strategies. Environ. Sci. Policy 63, 187-196. https://doi.org/10.1016/j.envsci.2016.06.001.

Fuchs, S., Röthlisberger, V., Thaler, T., Zischg, A., Keiler, M., 2017. Natural hazard management from a coevolutionary perspective: exposure and policy response in the European Alps. Ann. Am. Assoc. Geographers 107, 382-392. https://doi.org/10. 1080/24694452.2016.1235494.

Füssel, H.-M., 2007. Vulnerability: a generally applicable conceptual framework for climate change research. Global Environ. Change 17, 155-167. https://doi.org/10. 1016/j.gloenvcha.2006.05.002.

Hirschman, A.O., 1958. The Strategy of Economic Development. Yale Univ., Pr, New Haven.

Hirschman, A.O., 1967. Development Projects Observed. Brookings Institution Press, Washington, D.C.

Istat, 2018. 8milacensus. Una selezione di indicatori per ogni comune d'Italia. Available at: http://ottomilacensus.istat.it/documentazione/ (latest access on Jan. 12, 2018).

Kaufman, L., Rousseeuw, P.J., 1990. Finding groups in data: an introduction to cluster analysis, Wiley series in probability and mathematical statistics. Wiley, Hoboken, N.J.
Klein, J.A., Tucker, C.M., Steger, C.E., Nolin, A., Reid, R., Hopping, K.A., Yeh, E.T., Pradhan, M.S., Taber, A., Molden, D., Ghate, R., Choudhury, D., Alcántara-Ayala, I., Lavorel, S., Müller, B., Grêt-Regamey, A., Boone, R.B., Bourgeron, P., Castellanos, E., Chen, X., Dong, S., Keiler, M., Seidl, R., Thorn, J., Yager, K., 2019. An integrated community and ecosystem-based approach to disaster risk reduction in mountain systems. Environ. Sci. Policy 94, 143-152. https://doi.org/10.1016/j.envsci.2018. 12.034 .

Marin, G., Modica, M., Paleari, S., Zoboli, R., 2019. Disaster Risk Management: Building the 'Disaster Risk Assessment Tool' for Italy. SEEDS, Sustainability Environmental Economics and Dynamics Studies: Working Paper.

Martin, R., Sunley, P., 2015. On the notion of regional economic resilience: conceptualization and explanation. J. Econ. Geogr. 15, 1-42. https://doi.org/10.1093/ jeg/lbu015.

Modica, M., Zoboli, R., 2016. Vulnerability, resilience, hazard, risk, damage, and loss: a socio-ecological framework for natural disaster analysis. Web Ecol. 16, 59-62. https://doi.org/10.5194/we-16-59-2016.

Moran, P.A.P., 1950. Notes on continuous stochastic phenomena. Biometrika 37, 17-23. https://doi.org/10.2307/2332142.

Pagliacci, F., 2017. La pericolosità da disastri naturali nell'Italia rurale. Agriregionieuropa 13 (51), 16-21.

Pagliacci, F., Russo, M., 2019a. Multi-hazard, exposure and vulnerability in Italian municipalities. In: Borsekova, K., Nijkamp, P. (Eds.), Resilience and Urban Disaster: Surviving Cities. Edward Elgar, pp. 490-502.

Pagliacci, F., Russo, M., 2019b. Socioeconomic effects of an earthquake: does spatial heterogeneity matter? Regional Stud. 53, 490-502. https://doi.org/10.1080/ 00343404.2018.1462483.

Pagliacci, F., Russo, M., Sartori, L., 2017. Social innovation and natural disasters: the "Casa Italia" Plan. Sociologia Urbana e Rurale 87-102. https://doi.org/10.3280/ SUR2017-113006.

Peduzzi, P., Dao, H., Herold, C., Mouton, F., 2009. Assessing global exposure and vulnerability towards natural hazards: the Disaster Risk Index. Nat. Hazards Earth Syst. Sci. 9, 1149-1159. https://doi.org/10.5194/nhess-9-1149-2009.

Perroux, F., 1987. L'espace et le temps dans la théorie générale des unités actives. Economie Appliquée.

Russo, M., 1996. Units of investigation for local economic development policies. Éonomie Appliquée 85-118.

Russo, M., Silvestri, P., 2017. Dati e strumenti di analisi per ricostruire meglio. In: Esposito, F., Russo, M., Sargolini, M., Sartori, L., Virgili, V. (Eds.), Building Back Better: Idee e Percorsi per La Costruzione Di Comunità Resilienti. Carocci-Press online, Rome, pp. 107-114.

Schumacher, I., Strobl, E., 2011. Economic development and losses due to natural disasters: the role of hazard exposure. Ecol. Econ. 72, 97-105. https://doi.org/10.1016/ j.ecolecon.2011.09.002.

Shaw, R., Shiwaku, K., Izumi, T. (Eds.), 2018. Science and Technology in Disaster Risk Reduction in Asia: Potentials and Challenges. Academic Press, an imprint of Elsevier, London, United Kingdom.

UNDRO (Office of the United Nations Disaster Relief Co-ordinator), 1980. Natural disasters and vulnerability analysis: report of Expert Group Meeting (9-12 July 1979). [Geneva]: Office of the United Nations Disaster Relief Co-ordinator.

UNDRR United Nations Office for Disaster Risk Reduction, 2004. Living with Risk: a global review of disaster reduction initiatives. UNO-Verl, New York.

UNISDR United Nations Office for Disaster Risk Reduction, 2015. Sendai Framework for Disaster Risk Reduction 2015-2030.

UNISDR, United Nations Office for Disaster Risk Reduction, 2017. Disaster Resilience Scorecard for Cities. Available at: https://www.unisdr.org/we/inform/publications/ 53349 [latest accessed on: April, 05th 2018].

Valensise, G., Tarabusi, G., Guidoboni, E., Ferrari, G., 2017. The forgotten vulnerability: a geology- and history-based approach for ranking the seismic risk of earthquake-prone communities of the Italian Apennines. Int. J. Disaster Risk Reduct. 25, 289-300. https://doi.org/10.1016/j.ijdrr.2017.09.014.

Wisner, B., Blaikie, P., Cannon, T., Davis, I., 2004. At Risk: Natural Hazards, People's Vulnerability, and Disasters, 2nd ed. Routledge, London, New York.

Zimmermann, M., Keiler, M., 2015. International frameworks for disaster risk reduction: useful guidance for sustainable mountain development? Mt. Res. Dev. 35, 195-202. https://doi.org/10.1659/MRD-JOURNAL-D-15-00006.1. 